\title{
EDUCANDO AL PÚBLICO Y AL REY: UN CASO DE PERMISOS EN EL TEATRO DEI FIORENTINI DE NÁPOLES
}

\section{Educating the audience and the king: a case of licenses in the Teatro dei Fiorentini in Naples}

\author{
Ismael LÓPEZ MARTÍN \\ Universidad de Zaragoza \\ ilopezm@unizar.es
}

Fecha de recepción: 30/03/2017

Fecha de aceptación definitiva: 3/09/2017

RESUMEN: En la ciudad de Nápoles existieron varios teatros importantes durante el siglo XVIII, y algunos de ellos estaban especializados en la representación de obras en prosa o de ópera, como era el caso del Teatro dei Fiorentini y del Teatro di San Carlo, respectivamente. Aun asumiendo la prohibición real de representar cada género en el coliseo que no le correspondiera, algunos empresarios solicitaron del monarca una venia para hacer alguna excepción, como ocurrió con Giuseppe Coletta, del Fiorentini, que quería representar el Federico II de Comella, en prosa, en el San Carlo.

Palabras clave: Nápoles; Teatro dei Fiorentini; Federico II; Comella; teatro en prosa.

ABSTRACT: In the city of Naples there were several important theaters during the 18th century, and some of them were specialized in prose or opera, such as the Teatro dei Fiorentini and Teatro di San Carlo respectively. Even when aware of the royal prohibition on representing each genre in the coliseum that was not allowed, some promoters asked the monarch for a license, as did Giuseppe Coletta, of the Fiorentini, who wanted to represent Federico II, by Comella, in prose, in the San Carlo.

Kew words: Naples; Teatro dei Fiorentini; Federico II; Comella; theater in prose. 
La vida teatral del Nápoles virreinal de los siglos XVI al XVIII fue extremadamente rica, y para forjar esa riqueza desarrollaron un papel fundamental los espacios de representación, los teatros, que se erigían como los lugares en los que se escenificaban obras dramáticas según los géneros, aunque ello incluso supusiera algún conflicto puntual con la Corona.

Procede recordar cuál era la situación general que nos encontrábamos en la capital del Vesubio en el período dieciochesco para acercarnos al caso que explicaremos en estas páginas. El Teatro di San Giovanni dei Fiorentini (que durante gran parte del XVII fue conocido como el de la Commedia Spagnuola por el origen de las compañías que allí representaban sus piezas) ${ }^{1}$, el Teatro di San

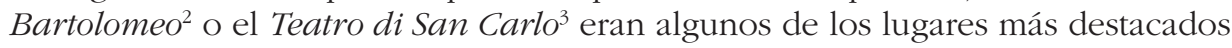
del municipio para representar, aunque no los únicos ${ }^{4}$. En estos teatros se establecía una distinción de género a la hora de poner en pie las obras: mientras que en el Fiorentini se representaban obras en prosa, en el San Bartolomeo y en el San Carlo tenían lugar montajes de óperas con música. De hecho, puede considerarse el San Carlo como el sucesor del San Bartolomeo, pues fue el rey Carlos VII de Nápoles (III de España) el que ordenó derruir este (que había sufrido un incendio en 1681$)^{5}$ para construir, en 1737 , uno de mayores dimensiones y grandiosidad, que hoy se ha convertido en el teatro de ópera en activo más antiguo del mundo.

Sin embargo, en algunas ocasiones, los empresarios de los teatros, constatando las necesidades y exigencias del público, pretendían representar obras de ópera en el Fiorentini, aunque parece que este conservó la característica de teatro en prosa hasta $1794^{6}$, si bien, evidentemente, esto no implica que no se montara allí ninguna ópera. En el Fiorentini se presentaban tanto óperas bufas como comedias ${ }^{7}$.

En estas páginas vamos a documentar un curioso suceso acaecido a finales del siglo XVIII y avalado por los intereses de un empresario teatral, que no estaban

1. Fue inaugurado en 1618 con El pastor Fido de Giovanni Battista Guarini, como cita PROTAGiurleo, Ulisse. I teatri di Napoli nel'600. La commedia e le maschere. Napoli: Fausto Fiorentino Editore, 1962 , pp. $71-72$.

2. Construido en 1621 con el fin de recaudar fondos para el Hospital de los Incurables, se inauguró con la comedia Li tre capitani vanagloriosi de Natale Consalvo. Allí representarían las compañías napolitanas y lombardas, según recoge ProtA-GIURLEO, Ulisse. I teatri di Napoli nel'600. La commedia e le maschere. Napoli: Fausto Fiorentino Editore, 1962, pp. 123-124.

3. Inaugurado en 1737, lleva el nombre del rey Carlos VII de Nápoles y III de España.

4. Otros teatros eran el de San Giorgio dei Genovesi, el Fondo, el Nuovo, el San Ferdinando, el San Carlino, las stanze de la Duchesca y de la Porta della Calce o el Ciardeniello de Fora Porta Capuana.

5. Croce, Benedetto. I teatri di Napoli. Dal Rinascimento alla fine del secolo decimottavo. Bari: Giuseppe Laterza \& Figli, 1916, p. 119.

6. Prota-Giurleo, Ulisse. I teatri di Napoli nel'600. La commedia e le maschere. Napoli: Fausto Fiorentino Editore, 1962, p. 117.

7. Mele, Eugenio. "Viaggiatori stranieri a Napoli. II. D. Leandro Fernández de Moratín». Napoli nobilissima. Rivista di topografía ed arte napoletana, 1906, XV, 5, p. 71. 
EDUCANDO AL PÚBLICO Y AL REY: UN CASO DE PERMISOS EN EL TEATRO DEI FIORENTINI DE NÁPOLES

demasiado alejados de los del público. Como se ha dicho, en el Teatro dei Fiorentini se venían representando las obras en prosa, y una función con Federico II, rey de Prusia de Luciano Francisco Comella traducida por Pietro Andolfati se llevó a las tablas del Fiorentini en los primeros meses de 1793, y parece que con notable éxito, tal y como consta en una solicitud de abril de ese año que Giovanni della Croce, de la compañía lombarda de dicho teatro, y Giuseppe Coletta, empresario del coliseo, dirigían al rey Fernando IV de Nápoles para solicitarle un permiso especial: poder representar en el Teatro di San Carlo, que estaba destinado a la ópera, el exitoso Federico II, en prosa:

S. R. M.

Signore

L'Impressario della Prosa Lombarda del Teatro de'Fiorentini, sup ${ }^{\text {do }}$ divotam $^{\text {te }}$ es'pme a V. M. di voler far rappresetare nel Real Teatro di S. Carlo in prosa i Dramma Intitolato Federico II, già rappresentato in quello de'Fiorentini, tan ben'accolto dal Publico, ed'onorato anco dalla Real Presenza della M. V., arrichendolo di maggiori decorazioni avendo perciò ottenuto il consenso dell'Impressario dell'anzid ${ }^{\circ}$ Real Teatro; Ricorre quindi el Sup ${ }^{\text {te }}$ da V. M. ed umilm ${ }^{\text {te }}$ la sup ${ }^{\text {ca }}$ a volersi compiacere di acordarse il suo sovrano real permesso, e Beneplacito, grazia dalla M. V. altra volta accordata alla Compagnia Francese, ut Deus.

Giovanni Della Croce sup ${ }^{\text {ca }}$ come sop ${ }^{\mathrm{a}}=$

Qualora vorrá benignarsi la suaestà $[$ sic] del Re /D. S./ accordare il Sovrano Suo Real Beneplacito all'Impres ${ }^{\text {rio }}$ della Prosa Lombarda del Teatro de' Fiorentini di far rappresentare nel Suo Real Teatro di S. Carlo il Dramma in Prosa int ${ }^{\circ}$ Federico II. io presto il mio consenso. Napoli li [sic] 9 Aprile 1793

Giuseppe Coletta ${ }^{8}$

Son varios los argumentos que se esgrimen para intentar conseguir el permiso del rey: el éxito de la obra, la intención de mejorar la escenografía en un nuevo montaje con las posibilidades que ofrecía el Teatro di San Carlo y un antecedente referido al mismo permiso que se concedió a una compañía francesa un tiempo antes:

animato quindi dall'esempio recente, di essersi rappresentato dalla compagnia Francese nello stesso $\mathrm{R}^{\mathrm{e}}$ Teatro un altro Dramma intitolato il Duca di Vandon, ne avanzò supplica a piedi del vostro Real Soglio, implorando una simile grazia in favore della su compagnia?.

8. Archivio di Stato di Napoli. Tribunali antichi, Generale Udienza di Guerra e Casa Reale (Serie Dispacci (AA. 1760-1808)), leg. 1670, fol. 48.

9. Archivio di Stato di Napoli. Tribunali antichi, Generale Udienza di Guerra e Casa Reale [Serie Dispacci (AA. 1760-1808)], leg. 1669, fol. 58. 
Además, se explicaba que el mismo rey había estado presente en la representación ofrecida en el Fiorentini; quizás los solicitantes pensaban que sería un argumento a su favor que el monarca asistiera al teatro y pudiera confirmar, si se diera el caso, el éxito del drama que ahora pretendía llevarse a un teatro en el que solamente se montaban óperas, al menos generalmente.

La respuesta de la Administración no se hizo esperar y el rey dictaba una real orden el 25 de abril en la que «non é venuto in accordare all'Impresario delle opere in prosa del Teatro de'Fiorentini il permesso, che Rachiesto di rappresentare in detto $\mathrm{r}^{\mathrm{l}}$ Teatro in prosa il Dramma, intitolato $=$ Federico Secondo $={ }^{10}$. Esa disposición fue trasladada a los solicitantes por Carlo di Marto el 11 de mayo, alegando, además, que no se trataba de un caso equiparable a la gracia concedida a la compañía gala: «il quale allegando si esempio, domanda il permesso di poter rappresentare in Prosa nel $\mathrm{r}^{\mathrm{l}}$ Teatro di S. Carlo il Dramma intitolato $=$ Federico II= che si era negato, in supposizione di non esservi stato simile esempio ${ }^{11}$.

La respuesta no parece que fue del agrado de los solicitantes, y el empresario del Fiorentini, Giuseppe Coletta, solicitó, el 22 de septiembre de ese mismo año, un permiso para poder representar obras tanto en prosa como con música ${ }^{12}$, cuya respuesta no nos ha sido posible localizar.

Sin embargo, casos como el que se ha descrito y otros (por ejemplo el de la compañía francesa que argüían Coletta y Della Croce en su solicitud) no hacían sino confirmar una tendencia que paulatinamente se asentaba en Nápoles: la adscripción de géneros a un teatro o a otro, que tanta tradición había tenido en la ciudad desde el siglo XVII, languidecía en las postrimerías del XVIII y en los albores del XIX.

\section{BIBLIOGRAFÍA}

Archivio di Stato di Napoli. Tribunali antichi, Generale Udienza di Guerra e Casa Reale [Serie Dispacci (AA. 1760-1808)], leg. 1669.

Archivio di Stato di Napoli. Tribunali antichi, Generale Udienza di Guerra e Casa Reale [Serie Dispacci (AA. 1760-1808)], leg. 1670.

Archivio di Stato di Napoli. Tribunali antichi, Generale Udienza di Guerra e Casa Reale [Serie Dispacci (AA. 1760-1808)], leg. 1699.

Croce, Benedetto. I teatri di Napoli. Dal Rinascimento alla fine del secolo decimottavo. Bari: Giuseppe Laterza \& Figli, 1916.

10. Archivio di Stato di Napoli. Tribunali antichi, Generale Udienza di Guerra e Casa Reale [Serie Dispacci (AA. 1760-1808)], leg. 1670, fol. 52.

11. Archivio di Stato di Napoli. Tribunali antichi, Generale Udienza di Guerra e Casa Reale [Serie Dispacci (AA. 1760-1808)], leg. 1669, fol. 58.

12. Archivio di Stato di Napoli. Tribunali antichi, Generale Udienza di Guerra e Casa Reale [Serie Dispacci (AA. 1760-1808)], leg. 1699, fasc. 15, núm. 15. 
EDUCANDO AL PÚBLICO Y AL REY: UN CASO DE PERMISOS EN EL TEATRO DEI FIORENTINI DE NÁPOLES

Mele, Eugenio. «Viaggiatori stranieri a Napoli. II. D. Leandro Fernández de Moratín». Napoli nobilissima. Rivista di topografía ed arte napoletana, 1906, XV, 5, pp. 70-74.

Prota-GIURLEO, Ulisse. I teatri di Napoli nel'600. La commedia e le maschere. Napoli: Fausto Fiorentino Editore, 1962. 